\title{
A New Project Management Performance Evaluation Method based on BP Neural Network
}

\author{
Wanyin Du \\ Department of Information Management, The Central Institute For Correctional Police, Baoding, \\ 071000, China
}

Keywords: BP neural network; Project management; Performance evaluation

\begin{abstract}
The traditional project management performance evaluation method mainly used single linear analysis, which is simple. But it can not reflect the complex non-linear relationship between the evaluations. Thus, a back propagation neural network model applied in project management performance was constructed, which considered four main control targets including project duration, quality, costs, and security. Through a case study, the evaluation results demonstrate that the proposed model is more comprehensive and can suit the actual situation closely, which can contribute to improving the project management level.
\end{abstract}

\section{Introduction}

Project management is a complex running system. It is not only affected by internal such as quality, cost, schedule, security and other aspects, but also by external influences such as social, economic, legal, natural and other environmental factors [1]. Project management performance evaluation is a very important and necessary link, enabling enterprises to perform all aspects of schedule control, budget adjustments, and other cost assessment correctly and improve the effectiveness and efficiency planned future projects assessment [2]. BP neural network with its parallel distributed processing, self-organizing, adaptive, unique self-learning excellent performance and fault tolerance, can better handle project management performance evaluation of multiple factors, uncertainty, complex nonlinear mapping problems [3]. Relying on the powerful BP neural network learning ability, data integration of a variety of factors, more accurate performance assessment values can be output via nonlinear transformation.

\section{BP neural network}

Artificial neural network from the origin to the present, no substantive progress on the connection weights of the problems in the research on the process. Then BP neural network is put forward, and provides a method to solve this problem.In the present stage in the field of artificial neural network , the application of BP neural network is still the most extensive.

In the ANN model, a multilayer feed-forward neural network model is the most widely used model. BP(Back Propagation) neural network is one of the most common multilayer feed-forward neural network model, this paper uses genetic algorithm to study the optimization of neural network.

BP (Back Propagation) network is a group of scientists led by Rumelhart and McCelland put forward in 1986 , is a kind of error back-propagation algorithm for training multilayer feed-forward network, its learning rule is to use the method of steepest descent, to constantly adjust the network weight value and threshold value by back propagation, make the network and the minimum sum of square error. BP neural network is mainly composed of an input layer, one or more hidden layers and one output layer, the mutual connection between the layers of neurons, but between each layer between the neurons are not connected relationship.

The learning process of the BP neural network model composed of by two parts,forward and backward .In the forward process of communication, information from the input layer through the middle hidden layer to the output layer weighted propagation, in the output layer to obtain the input of the network response, output value by comparing the function calculation and target output value, 
if there are errors, error back propagation along the route before the return, i.e., from the output layer after each intermediate the hidden layer to adjust the connection weights, finally back to the output layer, to reduce the error, with the neural network error reverse spread to revise the weights continuously, the entire network accuracy of input information in response to natural also improved .

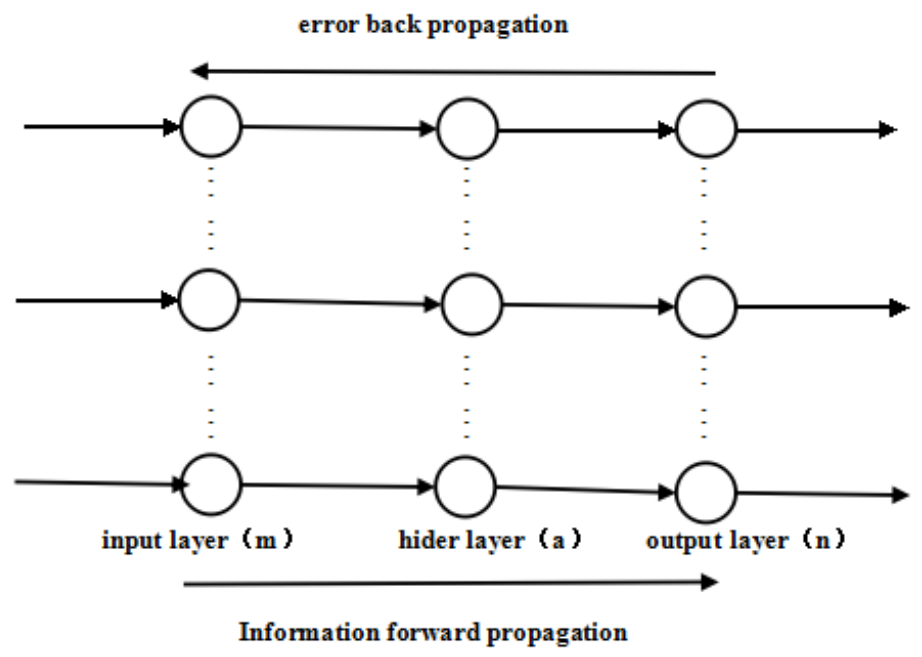

Figure 1.A classical 3-layer BP network model

The increasing function means that the multiplications of a node's all input and its corresponding connection are all added up. For example, the increasing function value of the first node in hidden layer is defined as below.

$$
x_{1}=\sum_{i} D_{i} w_{i 1}
$$

Where $x_{1}$ is the input value of the first node in hidden layer. $D_{i}$ is the input data of the $i$ th node in input layer. $w_{i 1}$ is the weight value from the $i$ th node in input layer to the first node in hidden layer.

The activation function means that the added value mentioned above function are transformed to the output value of the node through a certain mathematical method. For example, the output value of the first node in hidden layer is defined as below.

$$
y_{1}=g\left(x_{1}\right)
$$

Where $g(x)$ is named as activation function.

\section{Establishment of project performance evaluation and the utility function}

Factors affecting the performance of project management can be summarized in four aspects including schedule, cost, quality, and safety.

(1) Schedule represents construction production rate. The progress ahead of schedule may be used to indicate the progress rate control impact on project performance

(2) Cost control can be represented by the deviation of actual cost and forecasting cost.

(3) Quality control can be represented by a sum of quality passing rate in every part of the project.

(4) Safety control is mainly decided by the establishment of safety management system and the effectiveness in implementation process, which can be assessed by expert scoring method.

The nonlinear transformation function is used to transform the raw data into the utility evaluation value between $[-1,1]$. The utility function for individual indicators is defined as below.

$$
D_{i}=\frac{1-e^{-k y}}{1+e^{-k y}}
$$


Where $y$ is the relative ratio between evaluation actual value and the planned value.

\section{Performance evaluation of project management based on BP neural network model}

The network input layer nodes take 4 , and the utility function value represents the network input. The network output layer node defaults 1 , and uses $A$ to represent the project management performance output. According to the theory of neural networks and a lot of error of project management case study, the number of hidden layer and nodes are respectively taken 1 and $15 . \quad v_{i j}$ represents the connection weights between input layer and hidden layer. $w$ represents the connection weights between hidden layer and output layer.

The model operation steps are as follows:

(1) Define learning rate $\eta=0.01$; momentum factor $\alpha=0.1 ; v_{i j}$ and $w$ are random numbers between 0 and 1.

(2) Calculate for each unit output from the input layer to the output layer

(3) Compute the network error. If the actual error satisfies error requirements or achieve specified learning times, the study is finished. Otherwise, the following steps are continuing.

(4) Calculate the learning signal of every units layer by layer and correct weights according to the gradient descent direction.

(5) Transfer to the step three..

\section{Specific example analysis}

A certain company recently just completed a number of projects, and their basic data are shown in Table 1 . Then we evaluate these projects management performance.

Table 1. The basic data of proposed project

\begin{tabular}{|c|c|c|c|c|c|c|c|c|c|}
\hline \multirow{2}{*}{$\begin{array}{l}\text { Proj } \\
\text { ect } \\
\text { num } \\
\text { ber }\end{array}$} & \multirow{2}{*}{$\begin{array}{l}\text { Build } \\
\text { ing } \\
\text { area( } \\
\mathrm{m}^{2)}\end{array}$} & \multicolumn{2}{|c|}{$\begin{array}{l}\text { Schedule } \\
\text { control(day } \\
\text { ) }\end{array}$} & \multicolumn{2}{|c|}{$\begin{array}{l}\text { Cost } \\
\text { control } \\
\text { (Ten } \\
\text { thousand } \\
\text { RMB) }\end{array}$} & \multicolumn{2}{|c|}{$\begin{array}{l}\text { Quality } \\
\text { control } \\
\text { (Point) }\end{array}$} & \multicolumn{2}{|c|}{$\begin{array}{l}\text { Safety } \\
\text { control } \\
(\%)\end{array}$} \\
\hline & & $\begin{array}{l}\text { Plan } \\
\text { ned } \\
\text { value } \\
\text { s }\end{array}$ & $\begin{array}{l}\text { Act } \\
\text { ual } \\
\text { valu } \\
\text { e }\end{array}$ & $\begin{array}{l}\text { Plan } \\
\text { ned } \\
\text { valu } \\
\text { es }\end{array}$ & $\begin{array}{l}\text { Act } \\
\text { ual } \\
\text { valu } \\
\text { e }\end{array}$ & $\begin{array}{l}\text { Plan } \\
\text { ned } \\
\text { value } \\
\text { s }\end{array}$ & $\begin{array}{l}\text { Act } \\
\text { ual } \\
\text { valu } \\
\text { e }\end{array}$ & $\begin{array}{l}\text { Plan } \\
\text { ned } \\
\text { valu } \\
\text { es }\end{array}$ & $\begin{array}{l}\text { Act } \\
\text { ual } \\
\text { valu } \\
\text { e }\end{array}$ \\
\hline 1 & $\begin{array}{l}2359 \\
4\end{array}$ & 370 & 386 & 2167 & $\begin{array}{l}234 \\
2\end{array}$ & 86 & 90 & 3 & 0 \\
\hline 2 & $\begin{array}{l}1548 \\
7\end{array}$ & 240 & 267 & 1257 & $\begin{array}{l}104 \\
2\end{array}$ & 92 & 84 & 3 & 1 \\
\hline 3 & 3658 & 130 & 114 & 402 & 394 & 81 & 79 & 3 & 1 \\
\hline
\end{tabular}

(1) Compute the utility values of every control indicator.

According to the data in Table 1, the utility values of every indicators are calculated through Equation (1), and the calculation results are shown in Table 2.

Table 2. Results of utility impact of every indicators

\begin{tabular}{lllll}
\hline Number & Schedule & Cost & Quality & Safety \\
\hline 1 & -0.1235 & -0.0957 & 0.0266 & 0.2456 \\
2 & -0.0957 & 0.0635 & -0.0245 & 0.1657 \\
3 & 0.1134 & 0.0687 & -0.04 & 0.1475 \\
\hline
\end{tabular}

(2) Establish training samples.

Project Management performance evaluation training samples are established, and the performance evaluation provisions is $[-1,1]$, as shown in Table 3. 
Table 3. The samples settings

\begin{tabular}{llllll}
\hline \multirow{2}{*}{ Sample } & \multicolumn{2}{l}{ Control type } & \multicolumn{2}{l}{$\begin{array}{l}\text { Target } \\
\text { value }\end{array}$} \\
\cline { 2 - 5 } & Schedule & Cost & Quality & Safety & 1 \\
\hline 1 & 1 & 1 & 1 & 0 & 0 \\
2 & 0 & 1 & 0 & 1 & -1 \\
3 & -1 & 0 & 1 & -1 & 0.033 \\
4 & -0.2365 & -0.0687 & 0.0634 & 0.3657 & 0.089 \\
5 & 0.1635 & 0.0674 & -0.0365 & 0.134 & 0.089 \\
6 & 0.0897 & 0.0254 & -0.041 & 0.168 & -0.075 \\
7 & 0.2712 & -0.223 & 0.095 & 0.43 & 0.1615 \\
\hline
\end{tabular}

(3) Train and test the proposed model

According to the learning algorithm step, the 7 training samples shown in Table 3 are taken into the network to train the network repeatedly. The test results show that the the actual output is very close to the expected output and the mean square error $E$ is below 0.001 , which satisfied the error requirements. The test sample results are shown in Table 4.

Table 4. Test sample results

\begin{tabular}{llll}
\hline $\begin{array}{l}\text { Sample } \\
\text { number }\end{array}$ & Output value & Target value & $\begin{array}{l}\text { Relative } \\
\text { error(\%) }\end{array}$ \\
\hline 1 & 0.982 & 1 & 1.9 \\
2 & -0.0037 & 0 & 0.26 \\
3 & -0.989 & -1 & 1.13 \\
4 & 0.0313 & 0.033 & 0.02 \\
5 & 0.0919 & 0.091 & 0.29 \\
6 & -0.0759 & -0.074 & 0.089 \\
7 & 0.1621 & 0.1614 & 0.06 \\
\hline
\end{tabular}

(4) Calculate the values of project management performance evaluation

According to the trained neural network, the 3 project shown in Table 1 take the performance evaluation. Their network output values respectively are $-0.0249,-0.0947$ and 0.0289 . When the value equals zero, there is no bias between actual value and the planned value, which means performance of the project management is normal. When the value is below zero, the project management performance is considered poor. When the value is above zero, the project management performance is considered good.

\section{Conclusion}

The project management performance evaluation method based on BP neural network integrate the main factors that can affect the project management performance. The neural network can reflect the complexity of the nonlinear relationship among the project schedule, quality, cost, safety and project performance. Therefore, the proposed method makes project management performance evaluation more objective and effective.

\section{References}

[1] Farzana Asad Mir, Ashly H Pinnington. Exploring the value of project management: Linking Project Management Performance and Project Success. International Journal of Project Management. Volume 32, Issue2(2014), p.202-217.

[2] Jui-Sheng Chou, Jung-Ghun Yang. Evolutionary optimization of model specification searches between project management knowledge and construction engineering performance. Expert Systems with Applications. Volume 40, Issue 11(2013), p.4414-4426.

[3] Hu Junguo, Zhou Guomo, Xu Xiaojun. Using an improved back propagation neural network to study spatial distribution of sunshine illumination from sensor network data. Ecological 
Modelling. Volume 266, Issue 24(2013), p.86-96.

[4] CHAI Yi,YIN Hong-peng,LI Da-jie. BP neural network adaptive optimization design based on the improved genetic algorithm[J]. Chongqing university journal, 2007,30(4):91-96.

5] ZHANG Hongxia,SHEN Yuzhi,HANG Zhaoliang.Local government performance evaluation model based on fuzzy comprehensive

[6] Lei Huang,Shu-bi Zhang,Qiu-zhao Zhang .Application of particle swam optimization BP neural network to GPS elevation fitting[J].Journal of Geomatics,34（6）,2009,18-19.

[7] Jia-yang Wang ,Chun Guo,Zuo-yong Li .Preliminary evaluation model of mine safety based on neural networks optimized by particle swarm optimization[J].Journal of Computer Applications,30 (s1),2012,74-75.

[8] Quan LONG,Yong-qian Liu,Yong-pingYang.Fault diagnosis method of wind turbine gearbox based on BP neural network trained by particle swarm optimization[J].Acta Energiae Solaris Sinica,33(1),2012,121-123

[9] CAI Sijing; CHEN Haiyan; ZHENG Minggui.Evaluation of capacity of sustainable development of energy in Beijing based on GA-BP model[J].Journal of Liaoning Technical University(Natural Science),2009, 28(1): 5-9 